\title{
Vitamin C Mediated Minimisation of Malathion and Rogor Induced Mitoinhibition and Clastogeny
}

\author{
Q. Hoda, S. Bose and S. P. Sinha \\ University Department of Zoology, Bhagalpur University, Bhagalpur-812007, India
}

Accepted March 22, 1991

The roles of ascorbic acid (Vitamin C) as antimutagen, anticlastogen and anticarcinogen have been evaluated in various test-systems (Shamberger 1984). Under in vitro condition, it has been found to decrease the incidence of carcinogen-induced gene mutations (Guttenplan 1977, Raina and Gurtoo 1985), sister-chromatid exchanges (Galloway and Painter 1979), and chromosomal breakages (Gebhart et al. 1985, Shamberger et al. 1973). In humans, ascorbic acid prophylaxis has been reported to decrease chromosomal changes in peripheral lymphocytes of coal-tar workers occupationally exposed to polycyclic aromatic hydrocarbons and benzene (Sram et al. 1983). It (Vitamin C) has been shown to be anticarcinogenic in rodents previously treated with UV radiation, benzopyrene and nitrosocompounds (Ames 1983). The anticlastogenic property of this vitamin has been also found in in vivo mammalian systems (Sinha and Bose 1989, Hoda and Sinha 1990).

The present work is an attempt to evaluate such a role of ascorbic acid against pesticideinduced mitotic inhibition and clastogeny in the common tissue, i. e., onion-root tip cells.

\section{Materials and methods}

The role of ascorbic acid was checked when administered concurrently, as well as before and after the pesticide treatment. The doses of the pesticide ranged from the one to which the population is generally exposed to and upto that considered as maximum tolerable dose. (A) Pesticide used: Two commonly used formulations of organophosphorous pesticide, viz., Malathion (O-O-dimethyl phosphorodithioate of diethyl mercaptosuccinate, Cyanamid Company, India, which contains the active principle and emulsifiers in equal volume) and Rogor (O-O-dimethyl-S (N-methyl carbomoyl methyl) phosphorodithioate, Rallis-Tata, India, which contains $30 \%$ of the active principle and rest of emulsifiers and other surface active agents) were selected for the present work. The concentrations selected for both the pesticides were $0.01 \%, 0.02 \%, 0.04 \%, 0.08 \%$ and $0.16 \%(\mathrm{~V} / \mathrm{V})$ of the marketed formulation which in the case of Malathion amounts to $50,100,200,400$ and $800 \mathrm{ppm}$ and in the case of Rogor to $30,60,120,240$ and $480 \mathrm{ppm}$.

(B) Vitamin used: The source of vitamin $\mathrm{C}$ was synthetic injectable preparation of the sodium salt of L-ascorbic acid manufactured by Roche India Ltd, with trade name "Redoxon". The general recommended dose of the preparation for adult human being is $500 \mathrm{mg} / \mathrm{day}$. The dose of the vitamin used in the present study was $0.005 \%$, which is proportional to the normal human dose.

Onion (Allium cepa) bulbs were grown over jars in six groups, each containing five bulbs. When healthy young roots could come out to a length of about $1 \mathrm{~cm}$, they were subjected to treatment in two changes each of $24 \mathrm{hr}$ duration (Table 1). At the end of the second treatment in each group, three roots per bulb were cut, fixed in aceto-methanol (1:3) for $24 \mathrm{hr}$ and then preserved in $70 \%$ ethanol. Acetocarmine-stained squash preparations were made and the slides were screened for counting the number of dividing cells and locating abnormalities 
in them. In each set of experiment, the effect was observed in the count of at least three thousand cells in foci selected randomly following the method suggested by Bhalla et al. (1973).

\section{Results}

(A) Effects on mitotic-index:

This index was represented in the form of relative division rate (RDR) calculated by the formula given below:

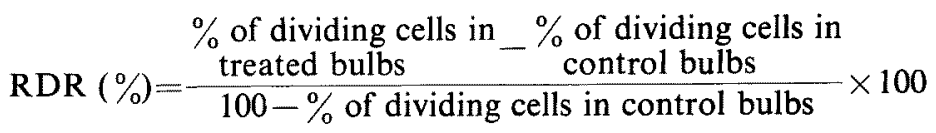

Negative value of RDR indicated mitosis inhibition.

Table 1. Mode of treatment with Vitamin and Pesticide

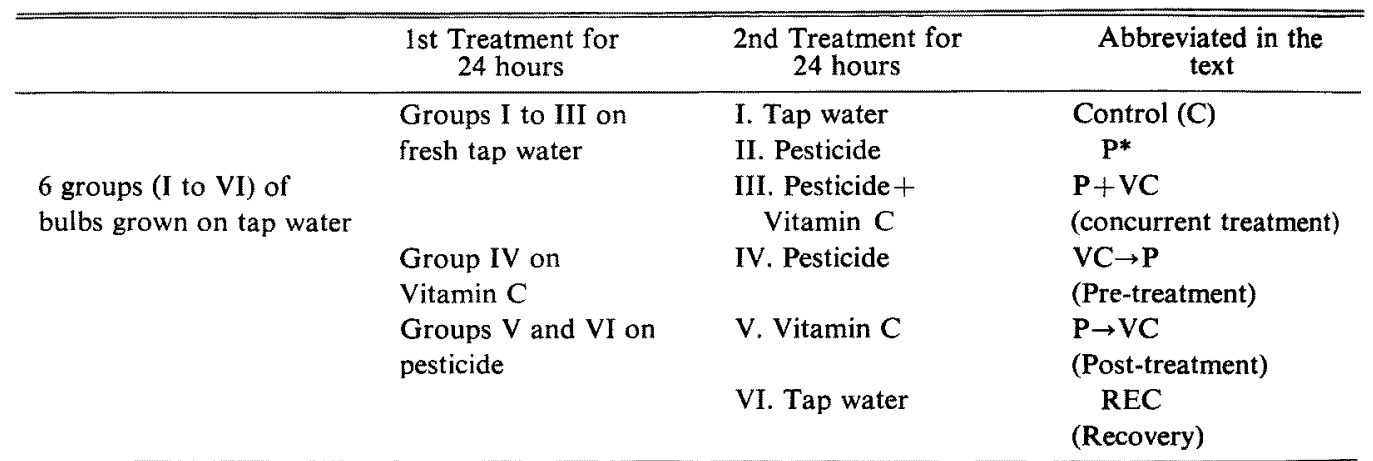

$\mathrm{P}^{*}$ was either Malathion (M) or Rogor (R) as the case may be.

(i) Effect of Malathion:

Significant decreases in RDR were noted (Fig. 1) in pesticide treated bulbs, and mitosis completely halted at $800 \mathrm{ppm}$ dose of the pesticide. In cases where pesticide and vitamin were administered concurrently $(M+V C)$, decreases in RDR were still observed but their intensity was much less. Pre-treatment with vitamin could not produce any significant protective effect against the mitoinhibitory effect of the pesticide $(\mathrm{VC} \rightarrow \mathrm{M})$. However, at the lower doses $(50$ and $100 \mathrm{ppm})$ it showed minimisation of the inhibition, though the decrease in RDR was still significantly lower than in the group treated with the pesticide only. When vitamin $C$ was given at the end of the pesticide-treatment $(\mathrm{M} \rightarrow \mathrm{VC})$, the pesticide-induced inhibition markedly decreased at the three lower doses; and surprisingly at $400 \mathrm{ppm}$ dose of the pesticide, the $R D R$ value showed increases over the control value $(R D R=+5.16)$. Even the mitosis which had completely ceased at $800 \mathrm{ppm}$ dose of the pesticide, got started in $\mathrm{M} \rightarrow$ $\mathrm{VC}$ group. The improvement in the division rate (as observed in $\mathrm{M} \rightarrow \mathrm{VC}$ group) may be the result of the withdrawal of the pesticide and/or of some protective effect of the vitamin itself. The recovery experiments (REC), no doubt, showed some improvement in division rate but its impact was not enough to discard the protective role of the vitamin.

(ii) Effect of Rogor:

Like Malathion, Rogor $(R)$ also decreased the division rate at all its concentrations and the decrease appeared to be dose-dependent (Fig. 2). In the R+VC group, the RDR at the two lower concentrations ( 30 and $60 \mathrm{ppm}$ ) was almost nearer to the control value ( $R D R=$ 


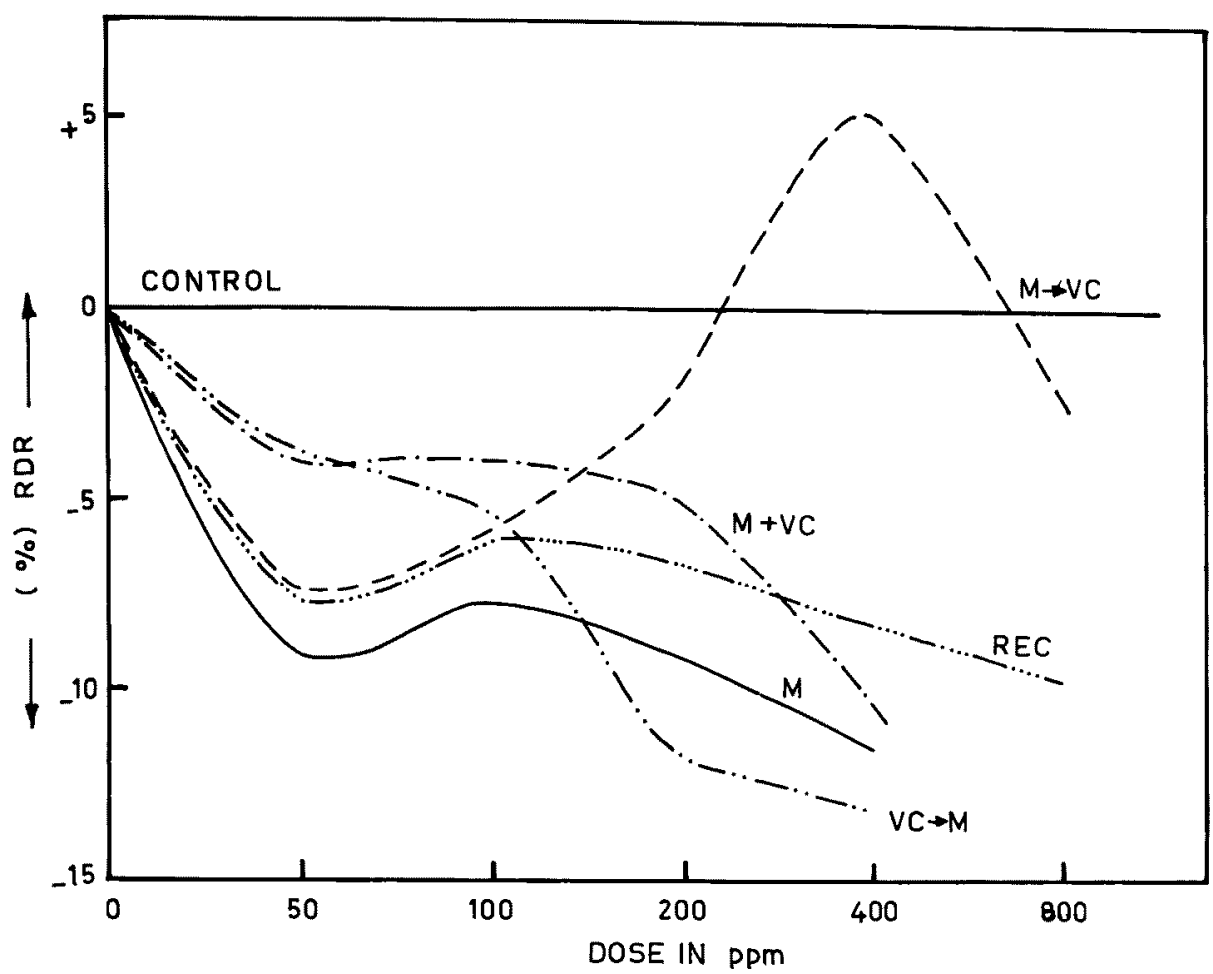

Fig. 1. Relative Division Rate (RDR in \%) in the root-tip cells of onion grown over different concentrations of Malathion with various modes of treatment with Vitamin C.

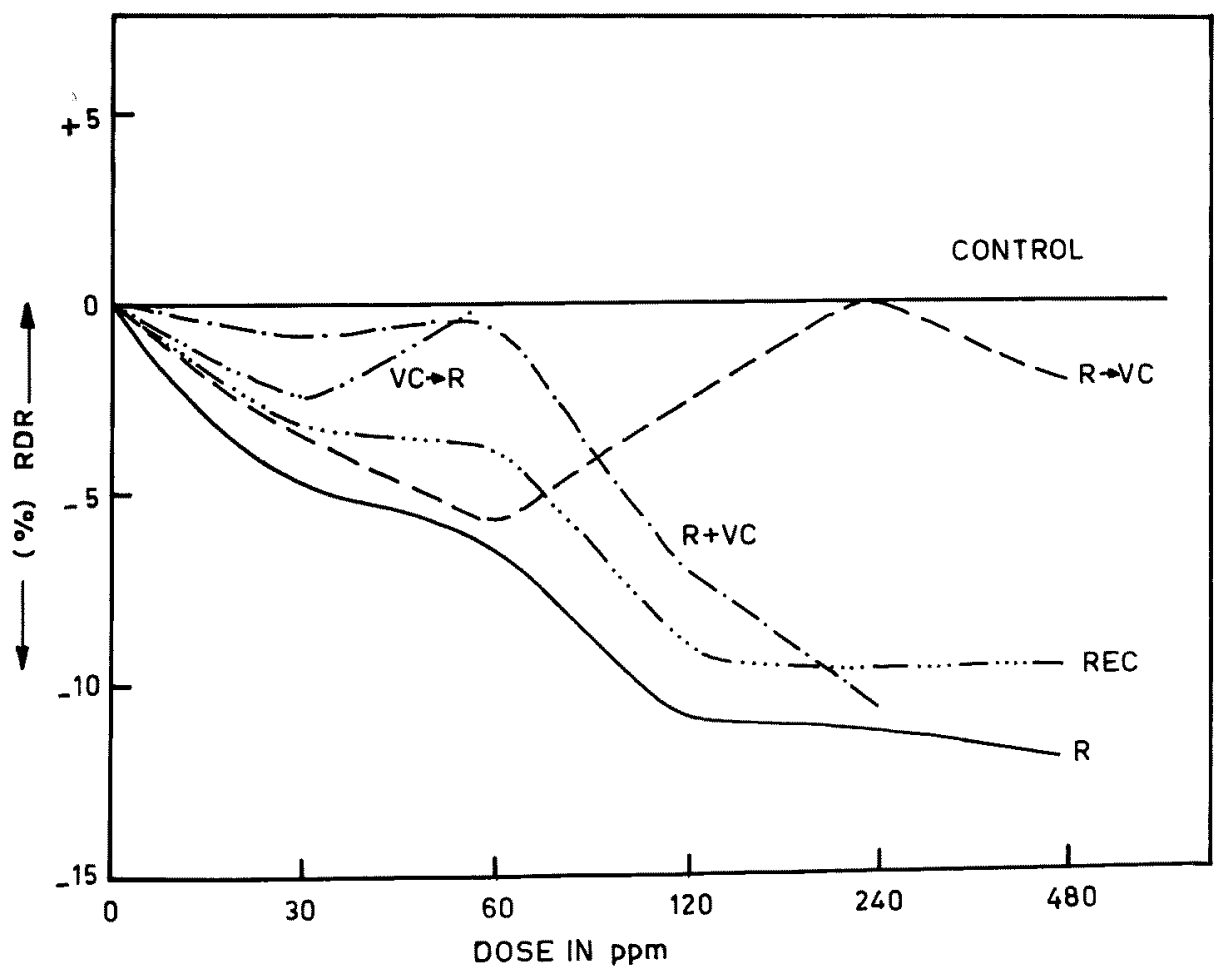

Fig. 2. Relative Division Rate (RDR in \%) in the root-tip cells of onion grown over different concentrations of Rogor with various modes of treatment with Vitamin $C$. 

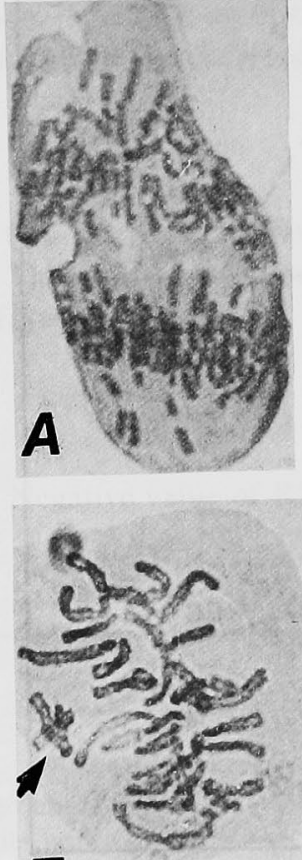

E
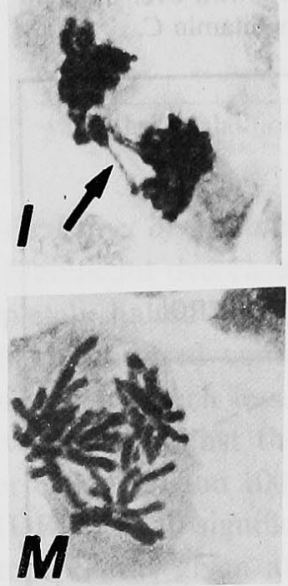

Q

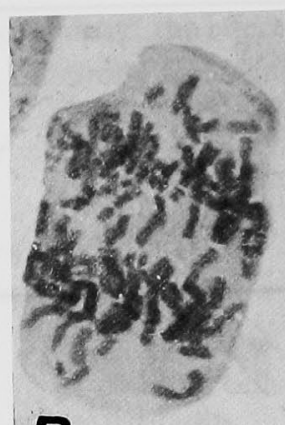

B
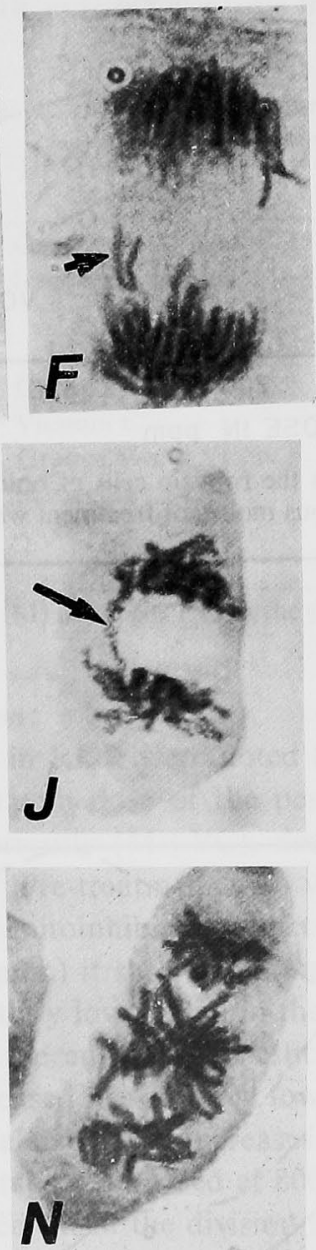

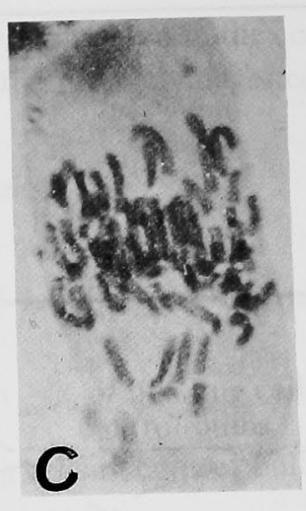

W. ox
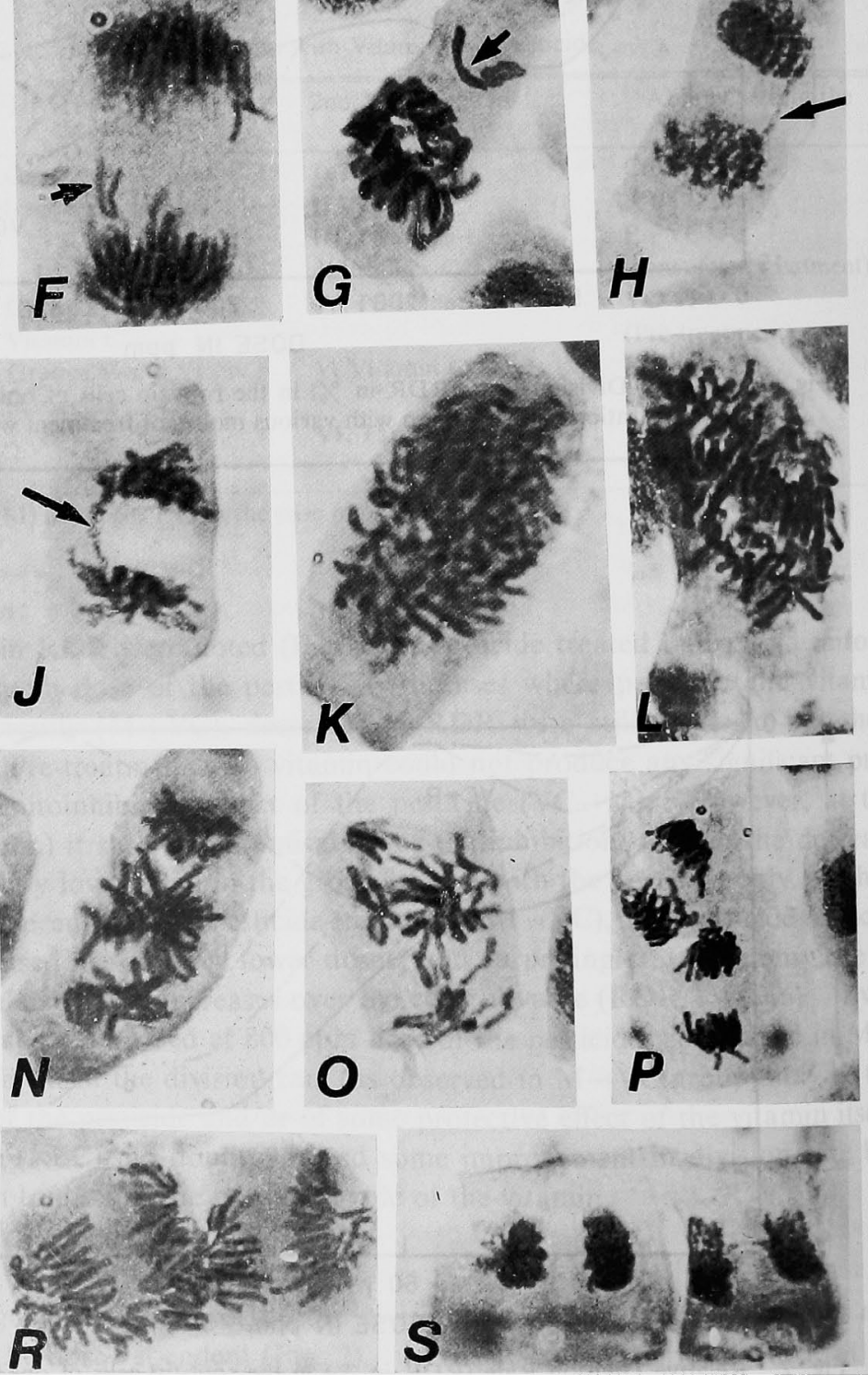

\section{H}
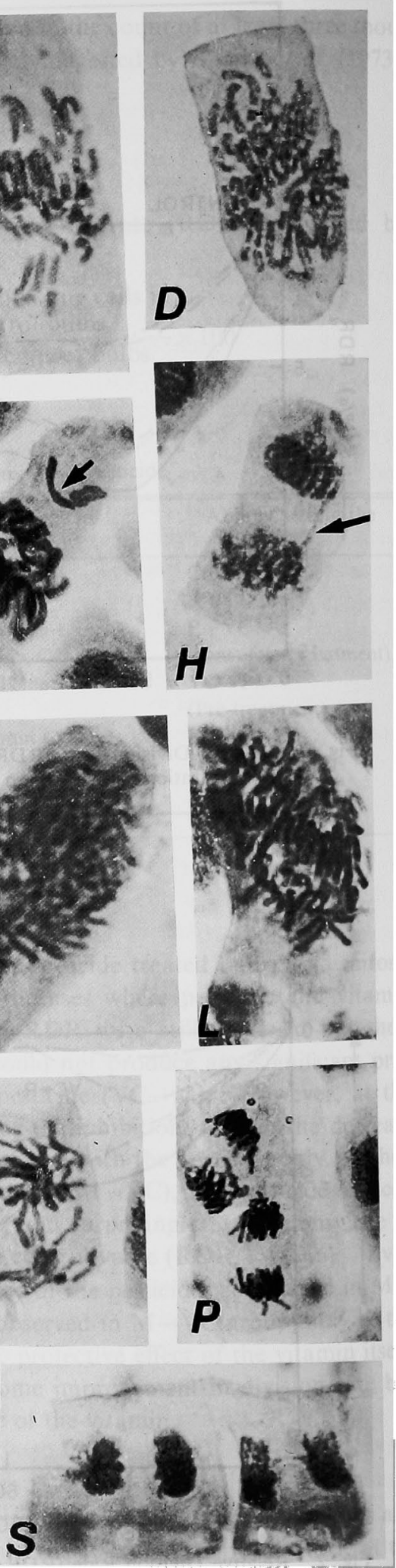
$-0.73,-0.92)$. However, at the two higher doses, significant decrease in RDR still persisted. Post-treatment with vitamin $\mathrm{C}(\mathrm{R} \rightarrow \mathrm{VC})$ was less effective in checking the inhibition at the three lower doses, but more so at the two higher ones $(\mathrm{RDR}=0.00,-2.03)$. In the $\mathrm{VC} \rightarrow$ $\mathrm{R}$ group, the cell division completely ceased at the three higher doses of the pesticide, but at the two lower doses $(30$ and $60 \mathrm{ppm}$ ) some improvement over the mitotic inhibition was found which was well marked at $60 \mathrm{ppm}$ dose of the pesticide. Data from recovery experiment (REC) also confirm the protective role of the vitamin against the pesticide induced mitoinhibition.

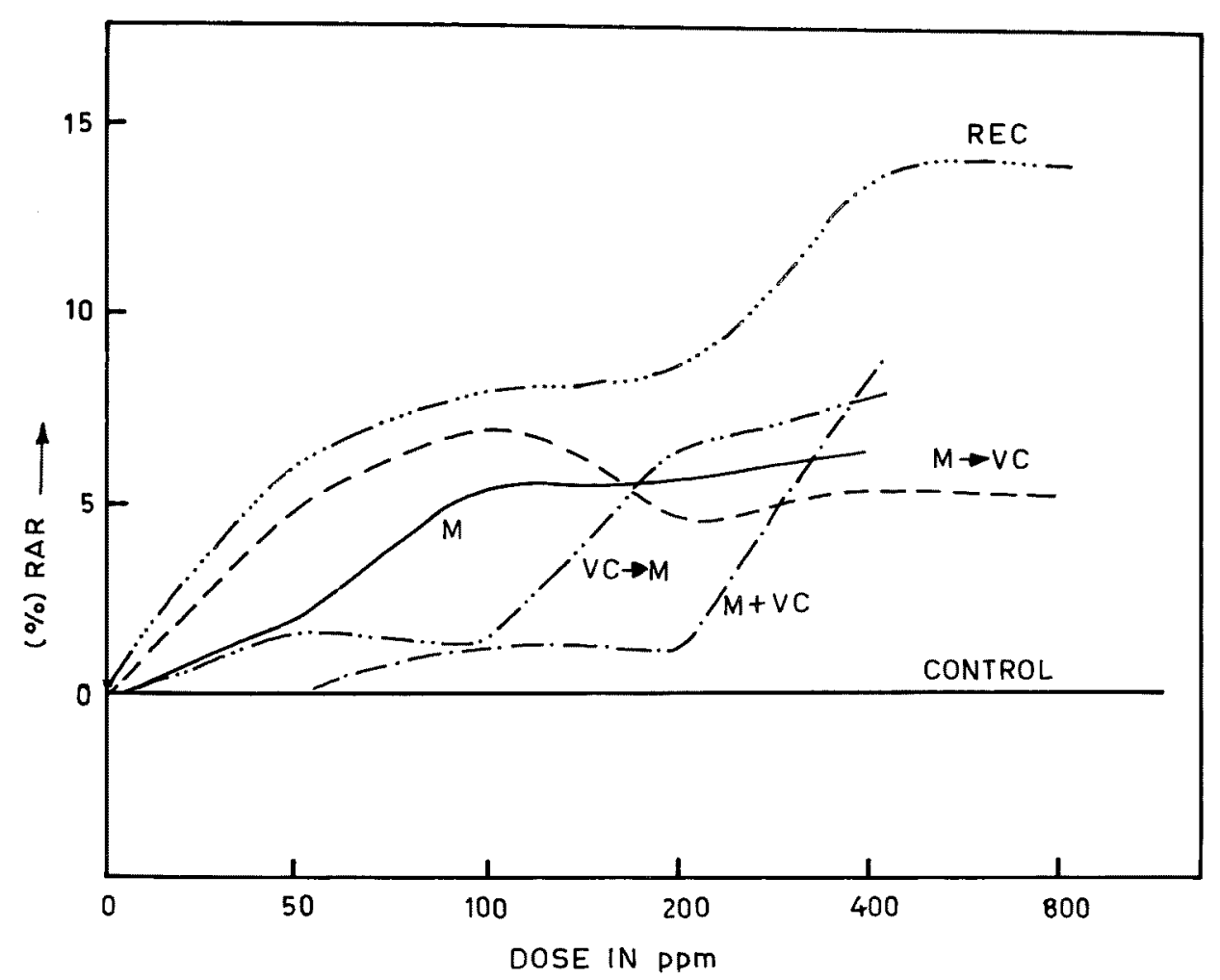

Fig. 4. Relative abnormality Rate (RAR in \%) in the root-tip cells of onion grown over different concentrations of malathion with various modes of treatment with Vitamin $C$.

Thus, it appears that the vitamin $\mathrm{C}$ produces some protective effect against pesticide induced mitoinhibition in root-tip cells and also that its concurrent treatment is more efficacious than any other mode of its supplementation. Results from analysis of variance (ANOVA) also confirm to this (at $\mathrm{P}<0.05$ ).

(B) Effect on mitotic chromosomes:

Pesticide-induced chromosomal abnnormalities can be broadly put into two categories: (a) chromosome/chromatid breaks and their subsequent re-arrangements mainfested as fragmentation, laggard, clumping and anaphase bridges, and (b) miscellaneous types such as multipolar spindles, polyploidy, disturbed cytokinesis, multinucleated cells and precocious separation of sister chromatids (Fig. 3).

Fig. 3. Chromosomal abnormalities induced by the pesticides in onion root-tip cells. A-D, fragmentation, E-G, laggards, H-J, anaphase bridge, $\mathrm{K}, \mathrm{L}$ polyploidy, $\mathrm{M}-\mathrm{O}$, multipolar spindle, P-S, disturbed cytokinesis $(\times 1000)$. 
(i) Effect of Malathion:

The incidence of chromosomal abnormalities significantly increased upon Malathion treatment and was directly proportional to the dose of the pesticide used (Fig. 4). When the vitamin was administered concurrently with the pesticide, no abnormalities could be seen at the $50 \mathrm{ppm}$ (lowest) dose of the pesticide; at the higher doses also significant decreases in the relative abnormality rate (calculated by the formula analogous to that used for RDR values) were observed. Pre-and post-treatments with vitamin also minimise the abnormality rate. In the recovery experiment, increase in the abnormality rate was observed, which suggests that the vitamin $\mathrm{C}$, at its own, is capable of minimising pesticide-induced clastogeny and other related abnormalities.

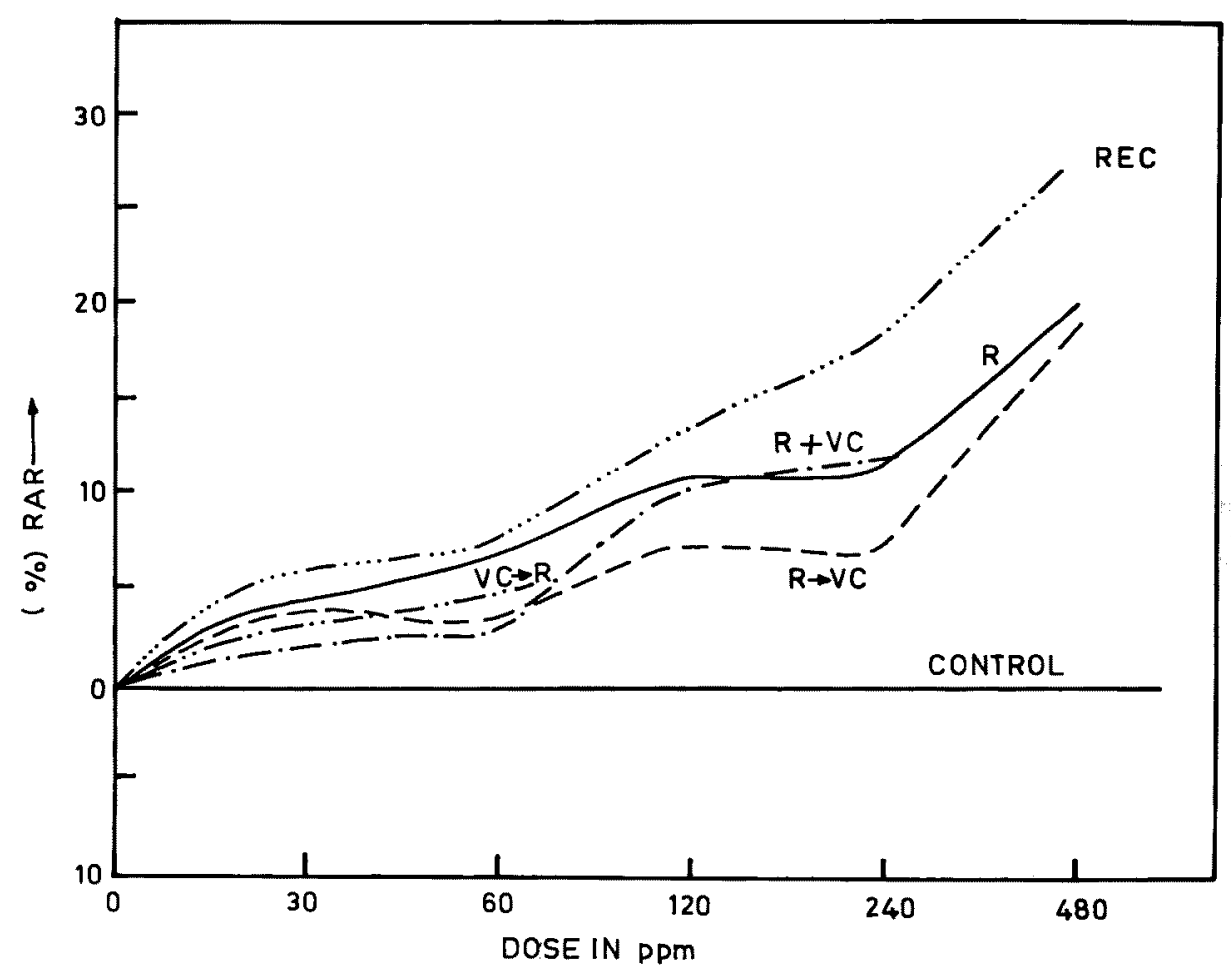

Fig. 5. Relative Abnormality Rate (RAR in \%) in the root-tip cells of onion grown over different concentrations of Rogor with various modes of treatment with Vitamin C.

(ii) Effect of Rogor:

The pattern of chromosomal abnormalities produced by Rogor was similar to that observed in the case of Malathion (Fig. 5). A definite trend of dose-dependence of abnormality rate was found. The various modes of supplementation of vitamin $\mathrm{C}$ and the recovery experiments showed a minimising effect as observed in the case of Malathion.

In order to understand the relative minimisation rate of break-related and miscellaneous types of abnormalities by the vitamin, the sum total of incidence of these abnormalities scored at all the doses of pesticide as well as vitamin treated bulbs were compared (Table 2). It appears that most (around 80 to $90 \%$ ) of the abnormalities caused by the pesticide are breakrelated, and as expected, most of the vitamin mediated (concurrent, pre- or post-treatment) decreases in their frequency were mainly due to decrease in the incidence of these very (breakrelated) damages. The result is strongly suggestive of the anticlastogenic nature of vitamin $C$. 
Relationship between Mitotic index and RAR:

The mitotic-index and abnormality rate as observed during the various modes of treatments with pesticide and vitamin showed negative correlation with each other (Table 3) except in the $\mathrm{VC} \rightarrow \mathbf{R}$ variant. This value was much higher in concurrent and pre-treatment variants with Malathion, but with Rogor in the concurrent variant only. The absence of correlation was noted only in those eventualities where the vitamins were used for post-treatment.

\section{Discussion}

The result presented suggest that mitotic inhibition as well as clastogeny induced by the pesticide can be appreciably minimised by the vitamin $\mathrm{C}$ and the concurrent treatment with the vitamin is more effective than any other mode of its supplementation.

Table 2. Cumulative abnormality rate $(\% \pm \mathrm{SE})$ for all concentrations of pesticide and vitamin administration in root-tip cells of onion

\begin{tabular}{|c|c|c|c|c|c|c|c|}
\hline \multirow{2}{*}{$\begin{array}{l}\text { Experi- } \\
\text { mental } \\
\text { groups }\end{array}$} & \multicolumn{3}{|c|}{ Abnormality Types $(\% \pm \mathrm{SE})$} & \multirow{2}{*}{$\begin{array}{l}\text { Experi- } \\
\text { mental } \\
\text { groups }\end{array}$} & \multicolumn{3}{|c|}{ Abnormality Types $(\% \pm \mathrm{SE})$} \\
\hline & Total & $\begin{array}{l}\text { Break- } \\
\text { related }\end{array}$ & $\begin{array}{l}\text { Miscel- } \\
\text { laneous }\end{array}$ & & Total & $\begin{array}{l}\text { Break- } \\
\text { related }\end{array}$ & $\begin{array}{l}\text { Miscel- } \\
\text { laneous }\end{array}$ \\
\hline$M$ & $4.68 \pm 0.91$ & $4.11 \pm 0.85$ & $0.57 \pm 0.32$ & $\mathbf{R}$ & $7.32 \pm 1.10$ & $6.60 \pm 1.04$ & $0.72 \pm 0.35$ \\
\hline $\mathbf{M}+\mathbf{V C}$ & $1.56 \pm 0.37$ & $1.32 \pm 0.34$ & $0.24 \pm 0.14$ & $\mathbf{R}+\mathbf{V C}$ & $4.47 \pm 0.61$ & $3.07 \pm 0.51$ & $1.40 \pm 0.34$ \\
\hline $\mathrm{VC} \rightarrow \mathrm{M}$ & $2.52 \pm 0.60$ & $2.52 \pm 0.60$ & nil & $\mathrm{R} \rightarrow \mathrm{VC}$ & $8.61 \pm 0.73$ & $4.44 \pm 0.53$ & $4.17 \pm 0.52$ \\
\hline $\mathrm{M} \rightarrow \mathrm{VC}$ & $5.95 \pm 0.57$ & $3.27 \pm 0.43$ & $2.70 \pm 0.43$ & $\mathrm{VC} \rightarrow \mathrm{R}$ & $4.16 \pm 0.75$ & $2.87 \pm 0.63$ & $1.29 \pm 0.42$ \\
\hline REC & $9.35 \pm 0.99$ & $5.38 \pm 0.77$ & $3.97 \pm 0.77$ & REC & $11.80 \pm 1.07$ & $7.57 \pm 0.88$ & $4.23 \pm 0.67$ \\
\hline
\end{tabular}

Table 3. The coefficient of correlation ( $r$ ) between the mitotic-index and relative abnormality rate as observed in different variants of experimentation

\begin{tabular}{clcc}
\hline Treatment type & \multicolumn{1}{c}{$\mathrm{r}$} & Treatment type & $\mathrm{r}$ \\
\hline $\mathrm{M}$ & -0.65 & $\mathrm{R}$ & $-0.88^{*}$ \\
$\mathrm{M}+\mathrm{VC}$ & $-0.99^{*}$ & $\mathrm{R}+\mathrm{VC}$ & $-0.99^{*}$ \\
$\mathrm{M} \rightarrow \mathrm{VC}$ & -0.49 & $\mathrm{R} \rightarrow \mathrm{VC}$ & -0.66 \\
$\mathrm{VC} \rightarrow \mathrm{M}$ & $-0.99^{*}$ & $\mathrm{VC} \rightarrow \mathrm{R}$ & $+0.98^{*}$ \\
$\mathrm{REC}$ & $-0.88^{*}$ & $\mathrm{REC}$ & $-0.84^{*}$ \\
\hline
\end{tabular}

* indicates significant correlation at $5 \%$ level of significance.

A successful completion of mitosis is a result of integrated harmoneous functions of the cell as a whole. Presence of pesticide molecules or their derivatives may disturb the synthesis or the structure of DNA (Mitchison 1977) or may cause inhibition of cell's entry into mitosis (Kihlman 1966) either by delay in onset of $\mathrm{G}_{2}$ (Gelfant 1963, Evans and Scott 1964, Waechter and Baserga 1982) and/or S-phases (Mitchison and Creanor 1971). Arrest of division would take place in most of these eventualities.

Pesticide-mediated alkylation of not only guanine but also of thymine, cytosine and uracil (Datta and Chedda 1980) and subsequent base-replacements is perhaps the most common mechanism of mutagenesis in micro-organisms, cells in culture or in experiments carried out in in vitro where almost unmodified pesticide molecules are available for causing the damage. In the higher organisms, the pesticides undergo a series of enzyme-mediated biotransformations and it is these biotransformed forms that have to be mutagenic. According to Hutson (1982), the fats and lipids present in the body/cells combine with pesticide metabolites to produce a conjugate type of chemical and it is believed that these conjugates have the real mutagenic nature. 
Vitamin C is well known to hydrolyse lipids and cholesterol (Rees and Slaten 1987, Fuzimoto et al. 1988, Wafer and Sies 1988, Koul et al. 1989). Hence the antimitoinhibitory and anticlastogenic effect of the vitamin $C$, as observed in the present case, may be due to this vitamin $\mathrm{C}$-mediated hydrolysis of the lipid/cholesterol, thus minimising the chances of the formation of mutagenic conjugate of pesticide with them.

\section{Summary}

Administration of vitamin $\mathrm{C}$, either concurrently or as pre-and post-treatment to the pesticide exposure, was very much helpful in minimising mitoinhibition and clastogeny induced by two organophosphorus pesticides, Malathion and Rogor. The concurrent treatment with vitamin $\mathrm{C}$ was more effective than the two other modes of its supplementation.

\section{References}

Ames, B. N. 1983. Dietary carcinogens and anticarcinogens. Science (Wash DC) 221: 1256-1264.

Bhalla, P. R., Kochar, T.S. and Sabharwal, P. S. 1973. Induction of mitotic abnormalities in onion roottips by tobacco smoke condensate (TSC). Cytologia 38: 707-712.

Datta, S. P. and Chedda, G. B. 1980. Synthesis and property of N-carbamoyl derivatives of cytosine, cytidine, uracil and thymine. J. Carbohydr. Nucleosides Nucleotides. 7: 217-240.

Evans, H. J. and Scott, D. 1964. Influence of DNA synthesis on the production of chromatid aberrations by $\mathrm{X}$-rays and maleic hydrazide in Vicia faba. Genetics: 49: 17-38.

Fuzimoto, Y., Sakamoto, N., Kitaura, H., Ikeda, E. and Fuzita, T. 1988. Stimulatory action of ascorbic acid on methyl-mercury induced lipid peroxidation in Rabbit kidney cortex. Chemical Pathology and Pharmacology. 60: 121-125.

Gallowy, S. H. and Painter, R. B. 1979. Vitamin C is positive in the DNA synthesis inhibition and sisterchromatid exchange tests. Mutat. Res. 60: 321-327.

Gebhart, E., Wagner, H., Girziwok, K. and Behsen, H. 1985. The action of anticlastogens in human lymphocyte cultures and their modification by rat-liver $\mathrm{S} 9$ mix. (ii) Studies with Vitamin $\mathrm{C}$ and $\mathrm{E}$. Mutat. Res. 149: 83-94.

Gelfant, S. 1963. Induction of cell-division, a critical and experimental analysis. Int. Rev. Cytol. 14: 1-39.

Guttenplan, J. B. 1977. Inhibition of L-ascorbate of bacterial mutagenesis induced by two nitrosocompounds. Nature. 268: 368-370.

Hoda, Q. and Sinha, S. P. 1991. Protective role of ascorbic acid and vitamin B-complex against pesticideinduced clastogeny in bonemarrow cells of mice. Int. Jour. for Vit. and Nutri. Res. 61 (in press).

Hutson, D. H. 1982. Formation of lipophilic conjugates of pesticides and other xenobiotics componds. "Progress in Pesticids Biochemistry." edt. Hutson, D. H. and Roberts, T. R. (John Wiley, N. Y.) Vol. 2: 171-184.

Kihlman, B. A. 1966. Action of chemicals on dividing cells (Prentice-Hall, Englewood Cliffs, N. Y.). 260.

Koul, A, Khandeja, K. L, Koul, I. B., Gupta, M. P., Majid, S. and Sharma, R. R. 1989. Effect of ascorbic acid on antioxidant defense systems and lipid peroxidation in guinea pigs. J. Clinical Biochem. Nutri. 6: $21-27$.

Mitchison, J. M. and Creanor, J. 1971. Further measurements of DNA synthesis and enzyme potential during the cell cycle of the fission yeast schizosaccharomyces pombe. Exp. Cell Res. 69: 244-247.

-, 1977 The timing of cell cycles events. "Mitosis Facts and Questions". edt. Little, M., Poweltz, N., Petzett, C., Ponstingle, M. Schroeder, D., Zimmermann, H. P. (Springer-Verlag, Berlin, Heidelberg, New York): 14-19.

Raina, V. and Gurtoo, H. L. 1985. Effects of vitamins A, C and E on aflatoxin $B_{1}$ induced mutagenesis in Salmonella typhimurium TA-98 and TA-100. Teratogen. Carcinogen. Mutagen. 5: 29-40.

Rees, S. and Slaten, T. F. 1987. Ascorbic acid and lipid peroxidation: the crossover effect. ACTA. Biochemica et. Biophysica Hungarica. 22(2-3): 241-246.

Sram, R. J., Dabias, L., Paster Kova, A., Rossner, P. and Janca, L. 1983. Effect of ascorbic acid prophylaxis on the frequency of chromosome aberrations in the peripheral lymphocytes of coal-tar workers. Mutat. Res. 120: 181-186.

Sinha, S. P. and Bose, Sulekha. 1989. Vitamin C mediated minimisation of clastogeny induced by dietary 
concentrations of aflatoxin. Harmful effect of Common environmental toxicants (Ed. O. Prasad), Allahabad University (India): 95-99.

Shamberger, R. J. 1984. Genetic toxicology of ascorbic acid. Mutat. Res. 133: $135-159$.

-, Baughman, F. F., Kalchert, S. L., Willis, C. E. and Hoffman, G. C. 1973. Carcinogen-induced chromosomal breakage decreased by antioxidants. Proc. Nat. Acad. Sci. USA, 70: 1461-1463.

Waechter, D. E. and Baserga, R. 1982. Genes and regulation of the cell cycle. in Genetic Expression in the Cell Cycle. Academic Press Inc. 23: 244.

Wafers, H. and Sies, H. 1988. The protection by ascorbate and glutathane against microsomal lipid peroxidation is dependent on Vitamin E. Europ. Jour. of Biochem. 175: 353-357. 